\title{
ЭКОНОМИЧЕСКАЯ МОДЕЛЬ ПОСРЕДНИЧЕСТВА В РОССИИ И ЗАРУБЕЖНЫХ ГОСУДАРСТВАХ (НА ПРИМЕРЕ США): ТЕОРЕТИКО-ПРАВОВОЙ АНАЛИЗ
}

\author{
(c) 2020 Фастова Марина Андреевна \\ кандидат юридических наук, доцент кафедры гражданского права \\ Астраханский государственный университет, Россия, Астрахань \\ E-mail: romanenkoma82@mail.ru
}

Настоящая статья посвящена теоретико-правовому исследованию посредничества в рамках его применения в экономических отношениях в зарубежных государствах на примере США. Данная модель посредничества получила наименьшее распространение и законодательное закрепление по сравнению с регламентацией посредничества при разрешении правовых конфликтов. Тем не менее, посредничество во всем его многообразии и формах в экономических общественных отношениях достаточно интенсивно развивается, усложняются посреднические связи, вводятся новые субъекты. Все это происходит на фоне все более модернизирующихся экономических отношений в целом, введения новых институтов, сфер, нуждающихся в правовой регламентации, и, как следствие, в дальнейшем детальном научном анализе.

Ключевые слова: посредничество, посредник, агент, брокер, представитель, законодательство, нормативный правовой акт, суд, гарантии, интересы.

Изменения, происходящие в экономических, политических, правовых общественных отношениях, показывают все возрастающую тенденцию роли права, его эффективные механизмы правоприменения, что, в конечном счете, направлено на объективную и всестороннюю реализацию правового статуса человека и гражданина, законных прав и интересов.

Происходящие процессы в формировании гражданского общества и правового государства как отображение реального закрепления правового статуса субъектов, формируют новые правовые институты, обозначают необходимость их детальной правовой регламентации, законодательного закрепления.

Проводимые преобразования в высокой степени должны соответствовать Основному закону нашего государства, предопределившему права и свободы человека высшей ценностью. Кроме того, с позиций научных исследований, они должны быть четко проработаны, иметь достаточную теоретическую методологическую базу.

Параллельно развивающаяся с законотворческой, научная деятельность характеризуется зачастую пробелами в области четкого определения любого предмета и объекта исследования, наличием разнообразных идеологических концепций, установлением теоретикометодологического плюрализма. Что, с одной стороны, расширяет научные и исследовательские края методологического поля, но с другой - требует от теоретической науки постоянного обновления ее методологического и концептуального инструментария. Одним из ярких примеров, названной тенденции в современном научном мире является посредничество, имеющее развитие в разных исследовательских направлениях и создающее возможности не только для исследований, проводимых по различным направлениям, но и усиливающее внедрение в предметные области разных научных сфер.

Дуализм трансформации посредничества в современном Российском государстве выражается в том, что с одной стороны происходит его активная законодательная регламентация, которая в большинстве случаев была ярко не выражена ранее, а, с другой стороны, отсутствие на должном уровне практики его применения в отдельных сферах, «отставание» реальных процессов от юридического закрепления, что неуклонно сопровождается рядом противоречий, вызванных объективной реальностью. В частности, это противоречия экономического характера, отсутствие комплексного научнотеоретического осмысления посредничества в данном ракурсе.

Часть противоречий, относящихся к экономическим тенденциям, и предопределили все 
больше обретающую актуальность посредничества в этой сфере. За последнее время российские экономические отношения интенсивно изменялись, модифицировались, принимая во внимание тот факт, что наиболее кардинальные изменения характерны для институциональной сферы.

По мере экономического возрождения России посредничество, синтезировав в себе передовые достижения теории распределения и товарного обмена, маркетинга и менеджмента, а также ряда других направлений, нуждается в системном подходе к организации рыночных трансакций на принципах оптимальности, рациональности, эффективности.

Тем самым, целью настоящей статьи выступает анализ посреднических отношений в сфере экономики, их исследование с позиций теоретико-методологического аспекта, выявление общих тенденций и направлений, а также фрагментарный анализ данной группы отношений в зарубежных государствах.

Другой ракурс противоречий условно можно свести к тому, что методологическое исследование посреднических отношений в экономическом секторе не нашло достаточно подробных исследований в теоретической науке, не являлось объектов отдельных научных трудов. Вместе с тем, термин «посредничество» достаточно часто применяется при анализе различных групп отношений в общественной жизни, в различных отраслевых науках. Таким образом, складывается парадоксальная ситуация: термин находит частое применение, но, вместе с тем, специфических научный, в том числе, концептуальный анализ отсутствует. Тем самым, посредничество в рамках экономических отношений выражается как locus communis («общее место»), не наполненное при этом конкретным содержанием. Теоретическая и методологическая ситуация выражена нехваткой рефлексии над уже имеющимися в научной жизни подходами к данной проблематике и необходимостью исследования теоретической мысли, а также внедрения теоретико-методологической стратегии исследования посредничества в экономических отношениях, которая автором определяется с позиции историко-правового, сравнительного и логического исследования, в ракурсе теоретикоправового анализа, центральным элементом которой в познании института посредничества мы видим структурный функциональный подход.
Достаточно много исследований как в отечественной, так и зарубежной литературе посвящено посредничеству при разрешении правовых конфликтов. Вместе с тем, посредничество в экономических отношениях, не подверженных конфликтологическому вмешательству, также требует научного осмысления.

Итак, посредничество исследуется в экономической науке, где неразрывно связывается с развитием экономических отношений в целом. Так, анализ экономической сферы общественных отношений, проводимый учёнымиэкономистами, показывает, что возможность устойчивого развития рынка, отвечающего требованиям и вызовам современных реалий, при определённых условиях своевременного осуществления структурных сдвигов существует. Вместе с тем, существующие в настоящее время экономические отношения, а также практика их применения характеризуются изменениями, нарушениями, кризисными состояниями, вызываемыми противоречиями экономического и рыночного характера.

В связи с чем, те изменения, противоречия, новые тенденции, характерные для экономической сферы общества, нуждаются в детальном исследовании и анализе. При этом предметом исследования выступают не только субъекты рыночных отношений, а также их взаимодействия, правовой статус, которые, по сути, и выявляют возникающие противоречия.

Противоречия в экономических отношениях являются неотъемлемой частью развития всего общества в целом, так как само наличие таких противоречий предопределяет существование источника развития. Развитие выстпает стимулом конкретного противоречия, но не противоречия в общем виде. В результате разрешения таких противоречий появляется импульс экономического роста, движения. Таким образом, рассуждая далее диалектически, можно сказать, что всякое развитие в самом общем виде ведет к противоречиям, к разрешению этих противоречий, а также к возникновению новых противоречий.

Само по себе развитие существующего объективного мира и познания происходит путём разделения единого и целого на части, на противоположные стороны, тенденции. Взаимофункционирование этих составных частей характеризуют систему как нечто целостное.

Известно, что единство противоположностей 
представляет собой один из ведущих законов диалектики. С другой стороны, любое противоречие - это не только взаимосвязь между противоположными частями или направлениями объекта или между самими противоположными объектами, но и отношение объекта к самому себе, так называемая самопротиворечивость объекта: «... если вещи присуща противоположность, то эта вещь находится в противоречии с самой собой; то же относится и к выражению этой вещи в мысли ...» [1].

Характеристика возникающий противоречий в большей степени зависит от специфических характеристик самих противоположных субъектов, а также от тех условий общественных отношений, в рамках которых разворачивается это их взаимодействие.

Противоречия в экономических отношения обусловлены противоположностью экономических интересов субъектов таких отношений, которые вступают между собой в экономические связи. И здесь важным становится вопрос о самой сути разрешения противоречий. Большинство возникающих противоречий предопределены такими общими признаками, как субъектно-объектными отношениями, противоречиями интересов, разделением на два типа антагонистические и неантогонистические.

Развитие рыночной экономики априори ориентировано на получение прибыли, соответственно, любую коммерческую сферу представляется возможным исследовать как область наращивания капитала. В функционировании того или иного участника рыночных отношений объективно возникает периодическая нехватка определенных ресурсов. Это может распространяться и на денежные, и на информационные аспекты. Но параллельно с этим есть участники, у которых эти ресурсы сосредоточены в большем, чем необходимо, объеме. Свободные ресурсы, не рассчитанные на потребление «здесь и сейчас», предопределяют наличие множества инвестиционных альтернатив внедрения.

В связи с вышеизложенным, посредники в экономических отношениях предстают как своеобразные «инструменты» для создания «трёх форм полезности: места, времени и приобретения, доставляя избыточные единицы ресурсов от одного субъекта рынка к другому, они обеспечивают доступность нужного ресурса в удобном месте и в нужное время» [2].

Что касается США, то и здесь мы видим не- однозначный подход к исследуемой категории. Термин «посредник» в англо-американском праве употребляется в разных значениях. Так, он часто используется при характеристике лица, которое «обеспечивает продвижение товаров и услуг от производителя к потребителю» [3], то есть действует в коммерческом обороте. К такого рода посредникам можно отнести две группы субъектов: первая группа: независимые оптовые и розничные фирмы; вторая: агенты и брокеры. Представители первой группы являются самостоятельными участниками, независимыми предпринимателями, которые имеют право собственности на продаваемый ими товар и которые осуществляют свою деятельность в своем интересе, а также за свой счет и от собственного имени. Вторые же, никогда не становятся собственниками продаваемого товара, они получают от производителей «комиссионные» за каждую заключенную ими сделку [4].

Торговый представитель как раз и выступает одним из видов таких агентов, «в задачу которого входит оказание покупателю услуг, связанных с приобретением и доставкой товаров» [5].

Брокеры могут быть охарактеризованы как особый вид агентов, получающие вознаграждение (комиссионные) за предоставление информации и оказания содействия при заключении сделок. Брокеры «реально содействуют расширению емкости рынка, принимают на себя значительную долю сбытовых издержек и гарантируют высокое качество обслуживания, способствую тем самым поддержанию торговой репутации продуцента» [6].

Следует отметить, что функционирование агентов, их правовой статус регулируется в большей степени прецедентным, а не статутным правом. Однако, в Англии применяется ряд законов, содержащих отдельные положения, затрагивающие определенные сферы функционирования агентов. К ним относятся: Закон о доверенностях 1971 г. [7], Закон о введении в заблуждение 1967 г. [8], Закон о праве собственности 1925 г. [9], Закон о коммерческих агентах 1993 г. [10] При применении Актов Парламента «Английские суды опираются главным образом на буквальное правило, которое исходит из точного прочтения каждого статута, а не из общего смысла» [11].

В США «для смягчения пестроты правовых норм и внесения в них некоторой ясности» [12] Американским институтом права создана част- 
ная кодификация гражданского права, которая имеет форму сборников, содержащих обобщения судебной практики по гражданским делам. Вопросам, связанным с регулированием агентских правоотношений, как формы посредничества в экономических отношениях, посвящен сборник «Restatement of the Law of Agency». Несмотря на то, что данная публикация носит частный характер, эта кодификация пользуется авторитетом в американских судах, которые зачастую ссылаются на эти сборники в принимаемых решениях.

Также необходимо отметить отсутствие в США единой законодательной базы в области посреднических отношений, в то время как «чем меньше непредсказуемого оставляет система законодательства в области коммерческих взаимоотношений, тем более уверенно они развиваются» [13].

Таким образом, проведенный анализ показывает, что теоретическая модель посредничества в экономических отношениях требует емкой научно-исследовательской базы, нуждается в детальном теоретико-правовом анализе. Причем это касается как самих посреднических отношений, так и правового статуса его участников, объектов правового регулирования.

\section{Библиографический список}

1. Маркс К. и Энгельс Ф. Соч., 2 изд. Т. 20. С. 640.

2. Финансовое посредничество коммерческих банков: монография / под научной ред. проф. Ю. В. Рожкова.Хабаровск: РИЦ ХГАЭП, 2011. С.7-8.

3. Rachman D.J., Merson M.H, Bovee C. L., Thill J. V. Business today. NewYork, 1990.P.346.

4. Загладина С.М. США: обращение товаров и услуг в экономике. М., 1975. С. 141-143.

5. Данненбург В., Монкриф Р., Тейлор В. Основы оптовой торговли. М., 2003. С.221.

6. Комлев С. Посреднические фирмы // Материально-техническое снабжение. 1989. № 5. С.70.

7. Powers of Attorney Act 1971, art. 5.

8. Электронный ресурс. URL: http://www.legislation.gov.uk (дата обращения: 04.07.2020).

9. Law of Property Act, [15 Geo 5, ch. 20.]L. 1996.

10. Электронный ресурc. URL: http://www.miripravo.ru (дата обращения: 04.07.2020).

11. Богдановская И. Ю. Закон в английском праве. М., 1987. С.95.

12. Нарышкина Р. Л. Источники гражданского и торгового права буржуазных государств. М., 1965. С.36.

13. Клучи Д. Государство, бизнес, экономика // США: экономика, политика, идеология. 1995. № 3. С.60. 